\title{
THE INFLUENCE AND DIFFERENCES OF ANTHROPOMETRIC CHARACTERISTICS AND MOTOR SKILLS IN TWO GENERATION STUDENTS IN THE ATHLETIC DISCIPLINE OF HIGH JUMP
}

\author{
Aleksandar Simeonov', \\ Mitrichka Dzambazovska-Stardelova ${ }^{1}$, \\ Ratko Pavlović ${ }^{i}$ \\ ${ }^{1}$ Faculty of Physical Education, \\ Sport and Health, University in Skopje, \\ Macedonia \\ ${ }^{2}$ Faculty of Physical Education and Sport, \\ University of East Sarajevo, \\ Bosnia and Herzegovina
}

\begin{abstract}
:
Anthropometric characteristics, motor skills as well as good technical performance are very important in the result of the athletic discipline - High Jump. Aim: The aim of this research was to determine the impact and differences in morphological characteristics and motor skills in athletic discipline high jump, at both generations of students at the Faculty of Physical Education, Sports and Health. In a sample of 100 respondents, consisted of full-time second year students at the age of 20 years with \pm of 6 months at the Faculty of Physical Education Sport and Health in Skopje. Divided into two groups 50 respondents in both generations surveyed - 2016 and 2018, research has been done. Methods: In our research for assessment of the morphological structure of the respondents, 14 morphological variables were used, and 5 motor variables for assessment of psychomotor abilities. The athletic discipline - high jump is used as a criterion variable. Results: From the obtained results of the regression analysis, we noticed that the morphological variables have a significant impact on the criterion variable - High Jump only in the first group of participants - 2016 generation $(\mathrm{Q}=0.008)$. Regarding the motor skills that were the subject of analysis in our research, we found that all five motor variables used as a test to test their abilities have a significant impact as a system on the criterion variable - High Jump $(\mathrm{Q}=0.000)$. According to the multivariate (MANOVA) and univariate analysis (ANOVA) of the results of both groups of entities, we noticed that both groups of respondents differ in their morphological characteristics and biomotor abilities $(\mathrm{Q}=0.000)$. Conclusion: Based on the results obtained from the applied research procedure, we came to the conclusion that the morphological structure of the
\end{abstract}

i Correspondence: email pavlovicratko@yahoo.com 
respondents has a significant role in achieving greater height in athletic discipline - High Jump. In terms of motor skills, we came to the conclusion that students should use the motor tests that were used in the research in the preparation phase, in order to be able to successfully meet the norm and achieve better results in the High Jump. The differences between the respondents would be smaller if they pay more attention to the preparation for the fulfillment of the norm in this athletic discipline, because from our experience so far, we can say that is the most difficult athletic disciplines for students.

Keywords: morphology, motor skills, high jump, analysis, impact, differences

\section{Introduction}

Athletics can practically be said to exist from the origin of man, because segments such as walking, running, jumping and throwing are an integral part of every person's daily life. Athletics in social life is considered a basic sport, which gives generations of all ages the basis for all movements, forms motor skills of all ages from an early age to people's recreational activities, especially in sports activities regardless of the sport (Radić, 2007).

At the Faculty of Physical Education, Sports and Health, athletics is represented by 15 athletic disciplines in the second year, the students take two colloquia with a presentation of the technique of athletic disciplines. At the end of the semester in May, a colloquium is used, which consists of five athletic disciplines - 100 meter sprint, long jump, shot put, high jump and 1500 meter running (athletic pentathlon). The colloquium contains norms for grades 6 to 10 according to the result achieved. With this colloquium we check the speed, strength, explosive force and endurance of the students, and of course the technical performance of the studied techniques of athletic disciplines (Radic \& Simeonov, 2013).

Analyzing the literature available to us, in relation to previous research in anthropometric characteristics and motor skills, some research is presented, which we consider to be related to our research. Radić, Simeonov, \& Raković (2014), analyzed certain anthropometric measures with an impact on sprint running. Using multivariate methods, he determined the influence of certain morphological variables - circumference of the thigh and lower leg and circumference of the upper arm and forearm. Kondrić, Duraković, \& Metikoš (2002), on a sample of 400 primary school students in Slovenia, applied 15 anthropometric variables and 24 motor tests in order to confirm the structural characteristics of morphology and motor abilities. Based on the obtained results, significant correlations between anthropometric characteristics, both the manifest variables and the latent dimension with the motor abilities are confirmed. The results of this research show that in every analysis of the motor space, the morphological space should be analyzed. Radić, \& Stojanović (2008) studied the influence of morphological characteristics on long jump and high jump. They found a connection between the system predictor variables and the influence of special morphological parameters - body weight, body height, upper arm circumference, lower leg, arm length. Stanković, et al. (2011), 
wanted to determine the impact of longitudinal and circular dimensions on the high jump result. The research was conducted on a sample of 30 students from VIII grade at the age of 14 years. A statistically significant correlation was established between the system of longitudinal dimensionality of the skeleton and the result in the high jump $(p<0.005)$. Čillik, Pupiš, Ďurják, Pavlović, et al. (2013), the aim of this study was to determine the impact and correlation between speed and speed endurance tests in student sprinters from an athletics club in Slovakia. The survey was conducted on a sample of seven athletes, aged 14 years. To assess the speed of the respondents, the tests of running 50 meters, acceleration speed (0-20 meters), maximum speed (20-40 meters) and 10 repetitions of squats on the jump ergometer - Myotest were used. The results showed that sprinters performed better than long-distance runners, yet they performed worse in speed endurance. From this it can be concluded that the timing of repetitions of squats is one of the key factors that significantly affect the speed and explosive force of athletes.

Miller, Herniman, Ricard, Christopher, et al. (2006), the aim of this study was to determine the impact of a six-week plyometry program on improving agility in athletes. The subjects were divided into two groups: control and experimental group that applied plyometry training. The control group was not divided into any special mode of operation while plyometric training was applied to the experimental group. Both groups underwent two agility assessment tests: the T-test and the Illinois agility test, as well as the strength platform test where the reaction time with the substrate was measured before and after the test. Univariate ANCOVA analysis was used to analyze the change in the results of scores (before and after), in the independent variables in the groups (experimental and control) with the scores and covariance. ANCOVA univariate revealed a significant group effect of F2.26 $=27.24, \mathrm{p}=0.000$. When comparing the group that applied plyometry training with the control group that was measured immediately after the agility test, significant group effects F2.26 $=7.81, p=0.002$ were found on the strength platform test. The experimental group reduced the contact time with the substrate compared to the control group.

The results of this study indicate that plyometry training has an effective effect on increasing agility in athletes. Asllani (2007), the aim of this study was to determine the impact of a 12-week plyometry program on improving results in long jump and high jump in students. The research was conducted on a sample of 220 respondents, first year students at a high school in Kumanovo. Respondents were divided into two groups: control and experimental group that applied plyometric training. The results of the canonical discriminant analysis and the multivariate analysis of the covariance of the initial and final measurement, indicate that the respondents from the experimental group under the influence of the transformation process for the development of explosive force made significant changes in the level of motor skills in athletic disciplines, long jump and high jump results. In another study, on a sample of 180 respondents, of which 90 students and 90 athletic athletes, aged 15 years, conducted a survey to determine the differences in the central regulation mechanism. A total of 8 motor tests were included to assess their abilities, of which 4 for speed assessment and 4 for endurance assessment. The results of 
the $\mathrm{t}$-test showed statistically significant differences $(\mathrm{p}<0.01)$ between the examined samples (Pavlović, Radić, \& Simeonov, 2013).

Nikolić (2001) analyzed programmed training for explosive force development. He confirmed that the three-month training process for the development of explosive force of the jump type significantly affects the quantitative changes of this motor dimension. Summarizing the obtained results, he came to the conclusion that the application of weightlifting technology in training for the development of explosive force contributes to development, and that heavyweight technology in addition to plyometric and complex training have an important place in the system, training for the development of explosive force. Simeonov, Radić, \& Stojanović (2015) analyzed the explosive force in vertical jumps as a factor for achieving high results. Important elements have been identified such as the speed of movement of the arms in the front position, the speed of the action of the spring foot in the reflection phase, as well as the angle of the upper leg with the lower leg, below which the jumper is reflected.

The goal of the research is to determine the impact and differences in morphological characteristics and motor skills in athletic discipline high jump, at both generations of students at the Faculty of Physical Education, Sports and Health.

\section{Material \& Methods}

The research was done on a sample of male respondents in two generations from the second year of the Faculty of Physical Education, Sports and Health, aged 20 years with a difference between them of \pm six months. Students are full-time students at the Faculty. The sample is a total of 100 entities, 50 students per generation. During the exam, all respondents were in good health and well tolerated biomotor loads during the exam. The research was conducted on the generations of 2016 and 2018.

Anthropometry is one of the examination methods - analysis of morphological characteristics. Data on individual characteristics of the human body are officially established by the International Biological Program (IBP). In order to realize the set goal of the research procedure, a total of 14 morphological features were used, as follows:

Longitudinal body dimension:

1. Body height $(\mathrm{ABH})$;

2. Leg length (ALL);

3. Arm length (AAL);

Body mass and volume:

4. Body weight (ABW);

5. Forearm circumference (AFAC);

6. Volume of the upper arm (AVUA);

7. Knee circumference (AKC).

Transversal body dimension:

8. Shoulder width (ASHW);

9. Hip width (AHW). 
Subcutaneous adipose tissue:

10. Skin flap of the abdomen (ASFA);

11. Skin flap of the upper arm (ASFUA);

12. Skin flap of the thigh (ASFT).

In order to evaluate the results of the entities in the athletic discipline - high jump, measurements of motor variables were conducted, which manifest speed, force, explosive force and repetitive force.

Motor variables for assessing the psychomotor abilities of the respondents:

1. Triple jump from a place (MTJP);

2. Throwing medicine ball overhead (MTMO);

3. Jump from a place (MJFP);

4. Abdominal musculature (MAM);

5. Swivel bends (MSB).

In the research, the athletic discipline - high jump was used as a criterion variable. The high jump is a manifestation of overcoming a vertical space, which the respondent should use a certain technique to jump as high as possible a bar.

Table 1: Norms and grades according to the achieved result (High Jump)

\begin{tabular}{|l|c|c|c|c|c|}
\hline Norms/Grades & $\mathbf{6}$ & $\mathbf{7}$ & $\mathbf{8}$ & $\mathbf{9}$ & $\mathbf{1 0}$ \\
\hline High Jump & $130 \mathrm{~cm}$. & $135 \mathrm{~cm}$. & $140 \mathrm{~cm}$. & $145 \mathrm{~cm}$. & $150 \mathrm{~cm}$. \\
\hline
\end{tabular}

The influence of morphological characteristics and motor skills on the criterion variable was determined using linear regression analysis. To determine the differences in the morphological characteristics and motor skills of the students from the 2016 generation, and from the 2018 generation, the following have been applied: multivariate analysis of variance (MANOVA) and univariate analysis of variance (ANOVA)

\section{Results}

Table 2: Regression analysis of High Jump with morphological variables (generation 2016)

\begin{tabular}{|l|c|c|c|c|c|}
\hline Variables & $\mathbf{R}$ & Part-R & BETA & T & Sig. \\
\hline ABH & 0,51 & 0,20 & 0,37 & 1,24 & 0,22 \\
\hline ALL & 0,43 & 0,02 & 0,03 & 0,11 & 0,91 \\
\hline AAL & 0,33 & $-0,24$ & $-0,34$ & $-1,51$ & 0,14 \\
\hline ASHW & 0,35 & 0,02 & 0,02 & 0,12 & 0,90 \\
\hline AHW & 0,50 & 0,22 & 0,24 & 1,38 & 0,18 \\
\hline ABW & 0,47 & 0,23 & 0,55 & 1,43 & 0,16 \\
\hline AVUA & 0,14 & $-0,28$ & $-0,39$ & $-1,77$ & 0,08 \\
\hline AFAC & 0,30 & $-0,17$ & $-0,22$ & $-1,04$ & 0,31 \\
\hline AKC & 0,36 & 0,24 & 0,34 & 1,50 & 0,14 \\
\hline ASFA & 0,32 & $-0,16$ & $-0,22$ & $-0,97$ & 0,34 \\
\hline ASFUA & 0,43 & 0,25 & 0,40 & 1,57 & 0,12 \\
\hline ASFT & 0,31 & $-0,23$ & $-0,32$ & $-1,46$ & 0,15 \\
\hline R=0.691 $\mathbf{R}^{2}=\mathbf{0 . 4 7 8} \mathbf{Q}=\mathbf{0 . 0 0 8}$ & \multicolumn{5}{|l}{} \\
\hline
\end{tabular}


The analysis of Table 2 shows a significant impact of the system prognostic variables of morphology on the criterion, as evidenced by the coefficients of multiple correlation $R=0.691$, variability coefficient $R^{2}=0.478$ and significance level $Q=0.008$. The value of multiple correlation explains the common variability between prognostic variables and the criterion of $47.8 \%$, with the remaining $33.2 \%$ remaining on other characteristics and other features that are not the subject of this research.

Table 3: Regression analysis of High Jump with motor variables (generation 2016)

\begin{tabular}{|c|c|c|c|c|c|}
\hline Variables & $\mathbf{R}$ & Part-R & BETA & $\mathbf{T}$ & Sig. \\
\hline MTJP & 0,08 & 0,11 & 0,13 & 0,76 & 0,45 \\
\hline MTMO & 0,28 & 0,15 & 0,17 & 1,03 & 0,31 \\
\hline MJFP & 0,43 & 0,30 & 0,37 & 2,09 & 0,04 \\
\hline MAM & $-0,30$ & $-0,39$ & $-0,42$ & $-2,79$ & 0,01 \\
\hline MSB & $-0,24$ & $-0,19$ & $-0,18$ & $-1,31$ & 0,20 \\
\hline
\end{tabular}

Motor variables as independent variables (Table 3) have a significant effect on the depending variable high jump, which can be determined by the values of the coefficients of multiple correlation $R=0.624$, the determination coefficient $R^{2}=0.389$ and the coefficient of significance $Q=0.00$. The overall variability between the independent system variables and the criterion variable explains the coefficient of determination by $38.9 \%$, while the other $61.1 \%$ belong to other characteristics and abilities that are not subject to analysis in the research. Variables with a special effect are: jump from a place, with a coefficient of significance (0.04) and abdominal musculature (0.01).

Table 4: Regression analysis of High Jump with morphological variables (generation 2018)

\begin{tabular}{|l|c|c|c|c|c|}
\hline Variables & $\mathbf{R}$ & Part-R & BETA & $\mathbf{T}$ & Sig. \\
\hline ABH & 0,44 & 0,13 & 0,30 & 0,82 & 0,42 \\
\hline ALL & 0,38 & $-0,03$ & $-0,05$ & $-0,17$ & 0,87 \\
\hline AAL & 0,39 & 0,04 & 0,09 & 0,26 & 0,80 \\
\hline ASHW & 0,55 & 0,34 & 0,44 & 2,17 & 0,04 \\
\hline AHW & 0,30 & 0,05 & 0,06 & 0,33 & 0,75 \\
\hline ABW & 0,38 & $-0,12$ & $-0,36$ & $-0,73$ & 0,47 \\
\hline AVUA & 0,35 & 0,12 & 0,20 & 0,73 & 0,47 \\
\hline AFAC & 0,31 & $-0,03$ & $-0,05$ & $-0,16$ & 0,88 \\
\hline AKC & 0,33 & $-0,03$ & $-0,07$ & $-0,16$ & 0,87 \\
\hline ASFA & 0,17 & 0,05 & 0,11 & 0,31 & 0,76 \\
\hline ASFUA & 0,11 & $-0,17$ & $-0,30$ & $-1,02$ & 0,31 \\
\hline ASFT & 0,22 & 0,25 & 0,40 & 1,60 & 0,12 \\
\hline R=0.614 R $\mathbf{2}^{\mathbf{0 . 3 7 7}} \mathbf{Q = 0 . 0 7 2}$ & \multicolumn{5}{|l}{} \\
\hline
\end{tabular}

From the analysis of where the values of the morphological characteristics of the respondents and the criterion of high jump from the coefficients of multiple correlation $\mathrm{R}=0.614$, the coefficient of determination $\mathrm{R}^{2}=0.377$ and the coefficient of significance level 
$\mathrm{Q}=0.072$ are shown, we can notice that the morphological prognoses variables do not have a significant effect on the criterion variable high jump (Table 4).

Table 5: Regression analysis of High Jump with motor variables (generation 2018)

\begin{tabular}{|l|c|c|c|c|c|}
\hline Variables & $\mathbf{R}$ & Part-R & BETA & T & Sig. \\
\hline MTJP & 0,55 & 0,25 & 0,27 & 1,69 & 0,10 \\
\hline MTMO & 0,51 & 0,28 & 0,29 & 1,95 & 0,16 \\
\hline MJFP & 0,28 & 0,04 & 0,04 & 0,28 & 0,06 \\
\hline MAM & 0,29 & $-0,11$ & $-0,11$ & $-0,71$ & 0,07 \\
\hline MSB & 0,46 & 0,25 & 0,28 & 1,68 & 0,10 \\
\hline $\mathbf{R}=\mathbf{0 . 6 1 3} \mathbf{R}^{\mathbf{2}}=\mathbf{0 . 4 0 3} \mathbf{Q}=\mathbf{0 . 0 0 0}$ & \multicolumn{5}{|l}{} \\
\hline
\end{tabular}

The analysis of the variables from the motor space (Table 5) as a system of prognostic variables have a significant impact on the criterion variable - high jump, as evidenced by the coefficients of multiple correlation $R=0.613$, the coefficient of determination $R^{2}=0.403$ and the level of significance $Q=0.00$. The coefficient of determination explains the common variability between the system of predictor variables and the criterion with $40.3 \%$, while the other $50.7 \%$ belong to other characteristics and abilities that are not the subject of the research.

Table 6: Multivariate analysis of variance - MANOVA

\begin{tabular}{|l|c|c|c|c|c|}
\hline & Value & F & Hypothesis df & Error df & Sig. \\
\hline Pillai's trace & 1,051 & 6,397 & 44,00 & 254,00 & 0,00 \\
\hline Wilks' lambda &, 180 & $7,755^{\mathrm{a}}$ & 44,00 & 252,00 & 0,00 \\
\hline Hotelling's trace & 3,257 & 9,253 & 44,00 & 250,00 & 0,00 \\
\hline Roy's largest root & 2,798 & $16,152^{\mathrm{b}}$ & 22,00 & 127,00 & 0,00 \\
\hline
\end{tabular}

Table 6 presents the measures that determine the differences between the two groups of respondents, which we claim according to the coefficients of Raov $\mathrm{F}$ approximation 16.152 with synergy $Q=0.00$ and Willks lambda $F=7.755$ and significance level of $Q=$ 0.00 .

Table 7: Univariate analysis of variance - ANOVA

\begin{tabular}{|l|c|c|c|c|c|c|}
\hline \multirow{2}{*}{ Variables } & \multicolumn{2}{|c|}{$\begin{array}{c}\text { I Group } \\
\text { (generation 2016) }\end{array}$} & \multicolumn{2}{c|}{$\begin{array}{c}\text { II Group } \\
\text { (generation 2018) }\end{array}$} & F & Sig. \\
& Mean & SD & Mean & SD & & \\
\cline { 2 - 5 } & 179,37 & 6,74 & 180,15 & 6,29 & 0,20 & 0,825 \\
\hline ABH & 59,48 & 3,23 & 56,82 & 3,09 & 10,17 & $\mathbf{0 , 0 0 ^ { * }}$ \\
\hline ALL & 84,98 & 4,88 & 83,18 & 4,32 & 5,45 & $\mathbf{0 , 0 1}^{*}$ \\
\hline AAL & 38,93 & 2,20 & 40,88 & 2,41 & 8,24 & $\mathbf{0 , 0 0}^{*}$ \\
\hline ASHW & 30,34 & 2,51 & 28,05 & 1,82 & 20,65 & $\mathbf{0 , 0 0 ^ { * }}$ \\
\hline AHW & 75,72 & 8,97 & 76,84 & 9,66 & 0,21 & 0,81 \\
\hline ABW & 30,28 & 2,80 & 31,38 & 2,92 & 3,69 & $\mathbf{0 , 0 3}$ \\
\hline AVUA & 37,50 & 2,51 & 37,99 & 2,58 & 1,33 & 0,27 \\
\hline AFAC & 55,16 & 3,50 & 56,34 & 3,78 & 1,42 & 0,25 \\
\hline AKC & & & & & \\
\hline
\end{tabular}


Aleksandar Simeonov, Mitrichka Dzambazovska-Stardelova, Ratko Pavlović

THE INFLUENCE AND DIFFERENCES OF ANTHROPOMETRIC CHARACTERISTICS AND MOTOR SKILLS IN TWO GENERATION STUDENTS IN THE ATHLETIC DISCIPLINE OF HIGH JUMP

\begin{tabular}{|l|c|c|c|c|c|c|}
\hline \hline ASFA & 11,99 & 5,29 & 6,51 & 1,50 & 24,29 & $\mathbf{0 , 0 0 ^ { * }}$ \\
\hline ASFUA & 8,27 & 3,25 & 5,65 & 1,74 & 23,42 & $\mathbf{0 , 0 0}^{*}$ \\
\hline ASFT & 7,99 & 3,41 & 12,78 & 5,61 & 12,63 & $\mathbf{0 , 0 0 ^ { * }}$ \\
\hline MTJP & 677,46 & 45,05 & 703,82 & 32,77 & 6,64 & $\mathbf{0 , 0 0 ^ { * }}$ \\
\hline MTMO & 9,18 & 1,24 & 10,32 & 1,55 & 7,09 & $\mathbf{0 , 0 0 ^ { * }}$ \\
\hline MJFP & 270,64 & 18,30 & 273,94 & 20,90 & 0,40 & 0,67 \\
\hline MAM & 26,44 & 6,70 & 31,18 & 6,27 & 13,22 & $\mathbf{0 , 0 0 ^ { * }}$ \\
\hline MSB & 9,52 & 2,22 & 9,98 & 2,39 & 1,21 & 0,30 \\
\hline Note: $\mathrm{p}<0.05^{*}$ & \multicolumn{7}{|l|}{} \\
\hline
\end{tabular}

From the analysis for determining the differences between the groups, we can noticed that the respondents from both groups differ in terms of morphological parameters in the following variables (Table 7): ALL - leg length $\mathrm{F}=10.17^{*}$, AAL - arm length $\mathrm{F}=5.45^{*}$, ASHW - shoulder width $\mathrm{F}=8.24^{*}$, AHW - hip width $\mathrm{F}=20.65^{*}$, AVUA - volume of the upper $\operatorname{arm} \mathrm{F}=3.69^{*}$, ASFA - skin flaps of the abdomen $\mathrm{F}=24.29^{*}$; ASFUA - skin folds of the upper $\operatorname{arm} \mathrm{F}=23.42^{*}$; ASFT - skin flap of the thigh $\mathrm{F}=12.63^{*}$.

These morphological variables make the greatest contribution to the differences between the two groups of entities.

From the motor variables in three variables, significant differences between the entities were determined, as follows: MTJP - triple jump from place $\mathrm{F}=6.64^{*}$, MTMO throwing medicine ball overhead $\mathrm{F}=7.09^{*}$, MAM - abdominal muscles $\mathrm{F}=13.22^{*}$.

\section{Discussion}

There are a number of studies comparing the impact of anthropometric characteristics and motor skills, which are related to certain athletic disciplines. Antekolović, Zufar, \& Hofman (2003) based on structural analysis explains that plyometric training or training for the development of explosive force and speed affects the development of strength as the ability and muscle speed of the legs and hips. Apart from the fact that this type of training affects the quality of the muscles, it also increases the value of the results in the basic manifestation abilities such as: jumps, start acceleration, sprints and movements by changing the direction of movement (agility) Jakoljević \& Batričević (2008). The aim of this study was to determine the quantitative differences between motor and functional abilities under the influence of an experimental model for the development of explosive force. The study was longitudinal in nature and lasted 8 weeks with 32 hours of training. Statistical analysis with t-test for small dependent samples and discriminant analysis was used to analyze the possible differences between the initial and final measurement between motor and functional abilities. It was found that the final measurement of the experiment showed a statistically significant difference from the application of the experimental model for the development of explosive force, mostly between motor variables for assessment of repetitive and explosive force and functional variables vital capacity of lungs and systolic and diastolic blood pressure. 
Živković \& Lazarević, (2011) investigated the effect of flexibility and explosive force on the result of long and high jumps. The sample of respondents consisted of primary school students aged 14 years, who in addition to regular physical education classes were included in the school sports section. 6 predictor variables were used: 3 measuring instruments for flexibility assessment, namely: deep bench leaning, sword and bat spark, and three measuring instruments for estimating the explosive force, namely: jump in distance from place, tripod from place and five-jump from place. The disciplines - long jump and high jump - were applied as a criterion system. The results showed that there is a statistically significant relationship between flexibility and explosiveness tests and jumping discipline tests $(\mathrm{p}<0.005)$. The results of this study indicate that tests for assessing flexibility and explosive strength have an effective effect on improving results in the jumping disciplines, and the same tests can be used by teachers and trainers to prepare students and athletes in the jumping disciplines. Bonacin, Blažević, Bilić, Kostovska, et al. (2012) set the goal to analyze the changes that occur in the latent space in 209 students aged 7-9 years, under the influence of transformational changes. The changes in the structure variation of the morphological dimensions obtained in three measuring points are analyzed. Between the initial, control and final measurement, a transformation process was realized lasting 18 months. Standard anthropometric measures for estimating morphological dimensions were applied to realize the research objectives. The system of anthropometric measures was factorized and the latent variables presented as predictors. The distance jump test, which assesses the explosive power of the lower extremities, was used as the criterion variable. The obtained results are processed by regression analysis. The results indicate that the system of defined latent dimensions had a statistically significant effect on the prediction of explosive force. However, from an informative point of view, they explain a very small part of the variability of the variance of the criterion variable $(5 \%, 11 \%$ and $10 \%)$. Therefore, the kinesiology program related to the development of explosive force should be planned and programmed in another way that is not directly related to the morphological latent dimensions in children of this age.

Petrović, Mihajlović, Smajić, \& Đinić (2012) on a sample of 60 male subjects, with a chronological age of 15 years ( \pm 6 months), divided into three groups of athletes of 20 , namely athletes, basketball players and soccer players, some motor tests were used to assess of the explosive force of a tensiometric platform "Kistler Quatro Jump 9290 AD: jumping from a squat position, jumps with outstretched legs, return jumps and the relative values of these jumps. athletes, while two significant discriminatory factors were separated from the discriminatory analysis. Asadi (2013) studied the effect of plyometric training on sprint and balance in different athletes. The research was conducted on a sample of 20 athletes, who were divided into two groups: an experimental group working on plyometrics and a control group. The plyometric training in the experimental group was performed twice a week for six weeks, where the athletes mostly did exercises in high jump, long jump and deep jumps. The 20-meter test was used to evaluate the sprint, while the Star excursion balance test (SEBT) was used for balance. After six weeks, the 
experimental group showed improvement $(\mathrm{p}<0.005)$ in the 20 -meter sprint test, while in the balance test there were no significant results, in the control group there was no improvement in the results of either test. Atanasković \& Georgiev (2014) aimed to determine the impact of myogenic weight training with explosive force on the lower extremities. The research was conducted on a sample of 36 respondents, students from a primary school in Leskovac, aged 11-14. The study was longitudinal in nature and lasted 6 weeks, two hours per week for 60 minutes. The main types of training to improve myogenic properties are plyometric training and classic myogenic training with weight load. The following parameters were measured using the Miotest by squat jump: jump height, jump energy consumed, jump strength and jump speed. The first group was control, and the second experimental group, both of 18 respondents. Based on the obtained results, the authors concluded that there is a statistically significant difference between the final and initial measurements in the experimental group, at the level of significance $(p=0.000)$. From the applied morphology, we noticed that in both groups of entities (respondents), there are generations that have high growth and body weight, which is a condition for rational lengths of the upper and lower extremities, as well as the volume of the upper arm and thigh.

Morphological characteristics, in addition to influencing the more successful manifestation of motor skills, should also be one of the conditions for the appearance of the candidate (student) who after graduating from the Faculty of Physical Education, Sports and Health, should work with a certain population from a different age before which with his appearance and attitude he should be an example for the educators.

Athletic discipline - high jump as an integral part of athletic pentathlon, is used in many faculties for the entrance exam, but also in athletics teaching. This discipline is a practical measure - a test to check the psychomotor ability - explosive force. Also, the discipline of high jump put finds application in checking physical abilities, in certain police units with special duties and in army structures.

It is for these reasons and the great importance of human motor skills that this athletic discipline has been the subject and aim of our research.

\section{Conclusion}

Based on the results obtained from the applied research procedure, we came to the conclusion that the morphological structure of the respondents has a significant role in achieving greater heights in athletic discipline - high jump. In terms of motor skills, we came to the conclusion that students should use the motor tests that were used in the research in the preparation phase, in order to be able to successfully meet the norm and achieve better results in the discipline - high jump. The differences between the respondents would be smaller if they pay more attention to the preparation for the fulfillment of the norm in this athletic discipline, because from our experience so far we can say that is the most difficult athletic disciplines for students. 


\section{Conflict of Interest}

The authors declare no conflict of interest.

\section{References}

Antekolović, Lj., Zufar, G. \& Hofman, E. (2004). Methodology for the development of explosive power such as jumping, International scientific-professional conference, Fitness training of athletes, Proceedings. 13, (7): 127-136, Faculty of Physical Education, University of Zagreb.

Asadi, A. (2013). Effects of seasonal plyometric training on sprint and balance for basketball performance. Sport science. 6 (1): 24-27.

Asllani, I. (2007). Uticaj eksplozivne snage na rezultatsku efikasnost $u$ daljinskim skokovima kod omladinaca, [Influence of explosive power on result efficiency in long jumps in young people. In Serbian] Doktorski rad, Fakultet za sport i turizamNovi Sad.

Atanasković, A. \& Georgiev, M. (2014). Influence of programmed strength training on explosive power of the lower extremities in children aged 11-14 years. TIMS Acta. 8 (2): 147-154.

Bonacin, D., Blažević, S., Bilić, Ž., Kostovska, Z., Bonacin, D. (2012). Changes in the latent morphological dimensions and the explosive force of the feet in boys aged 7-9, International journal of scientific issues in physical education, sport and health. Research in Physical Education, Sport and Health. 1 (2): 39-42.

Čillik, I., Pupiš, M., Ďurják, O., Pavlović, R., \& Bonacin, D. (2013). Speed and speedstrength abilities of the representatives for Slovakia in short-distance runs in pupils category in Athletics, Sport Science. 6 (1): 38-43.

Jakoljević, D. \& Batričević, D. (2008). Effects of explosive power model for development on motor and functional abilities of students, Sport Science. 4(2): 31-37.

Kondrić, M., Duraković, M. \& Metikoš, D. (2002). Contribution to the knowledge of the relations of morphological and motor characteristics of 7-19 year old students. Kinesiology. 34 (1):38-43.

Miller, M. G., Herniman, J. J., Ricard, MD., Christopher, C., Cheatham and Timothy J. Michael (2006). The Effects of a 6-Week Plyometric Training Program on Agility. Journal of Sports Science and Medicine. 5 (3):459-465.

Nikolić, B. (2001). Analysis of the effectiveness of specifically programmed training for the development of explosive power of the jumping type in basketball players, Kinesiology for the 21st Century. 9(2): 42-51.

Petrović, M., Mihajlović, I., Smajić, M., Đinić, I. (2012). Differences in indicators of explosive power of lower extremities of athletes of different sports activities. Acta Kinesiologica. 6 (1): 66-72. 
Pavlović, R., Radić, Z. \& Simeonov, A. (2013). Differences in anthropological space of jumpers finalists of the Beijing Olympics. Research in Physical Education, Sport and Health. 2 (2): 73-79.

Radić, Z., \& Simeonov, A. (2006). Athletics - technique. Publishing company Alkom, Skopje.

Radić, Z., \& Simeonov, A. (2013). Athletics - Methodology. Publishing company Alkom, Skopje.

Radić, Z. \& Simeonov, A. (2009). Relations between morphological characteristics and results in the jumping discipline. In Proceedings FIS Communications. 7(2): 16-22.

Radić, Z. and Simeonov, A. (2014). Influence of motor variables on the result in the long jump in athletic pentathlon, International Magazine for Track and Field. 13 (2):28-35. Sofia.

Radić, Z., Simeonov, A. \& Rakovic, A. (2014). Comparative analysis of the structure of the morphological, basic and specific motor space, Faculta humanitnych vied Slovenska asocijacija Kondicnyh trenerov, recenzovany vedecky zbornik z medzinarodney vedeckey konferencie kondicny Trening, Univerzitet Mateja Bela, Banska Bistrica, 14, (1): 58-64.

Stanković, D., Joksimović A. \& Raković, A. (2011). The Influence of Longitudinal and Circular Dimensions on the Results of Long Jump. Research in Physical Education, Sport and Health. 1 (2): 22-29.

Simeonov, A., Radić, Z. \& Stojanović, T. (2015). Explosive power as an indicator of success in vertical jumps, Research in Physical Education, Sport and Health. 1 (2): 123-128.

Wolfgang, R., \& Harald, M. (2017). Run, Jump, Throw. The official IAAF Guide to Teaching Athletics, (pp.113-152).

Živković, M. \& Lazarević, V. (2011). Influence of the flexibility and explosive power on the results in sprint disciplines, Research in Physical Education, Sport and Health. 1 (2): 123-128. 
Aleksandar Simeonov, Mitrichka Dzambazovska-Stardelova, Ratko Pavlović

THE INFLUENCE AND DIFFERENCES OF ANTHROPOMETRIC CHARACTERISTICS AND MOTOR SKILLS IN TWO GENERATION STUDENTS IN THE ATHLETIC DISCIPLINE OF HIGH JUMP

Creative Commons licensing terms

Authors will retain the copyright of their published articles agreeing that a Creative Commons Attribution 4.0 International License (CC BY 4.0) terms will be applied to their work. Under the terms of this license, no permission is required from the author(s) or publisher for members of the community to copy, distribute, transmit or adapt the article content, providing a proper, prominent and unambiguous attribution to the authors in a manner that makes clear that the materials are being reused under permission of a Creative Commons License. Views, opinions and conclusions expressed in this research article are views, opinions and conclusions of the author(s). Open Access Publishing Group and European Journal of Physical Education and Sport Science shall not be responsible or answerable for any loss, damage or liability caused in relation to/arising out of conflict of interests, copyright violations and inappropriate or inaccurate use of any kind content related or integrated on the research work. All the published works are meeting the Open Access Publishing requirements and can be freely accessed, shared, modified, distributed and used in educational, commercial and non-commercial purposes under a Creative Commons attribution 4.0 International License (CC BY 4.0). 